\title{
Application of computer vision art based on emoticons in the field of animation
}

\author{
Yang $\mathrm{Cao}^{1, *}$, Yuxin Wang ${ }^{1}$ \\ ${ }^{1}$ Dalian University of Science and Technology, Dalian, Liaoning, China, 116052
}

\begin{abstract}
Starting from the overview, this article explains the connotation of computer vision art and computer animation, and discusses the practical application of computer vision art in emoticon animation, in order to reflect the charm of the integration of technology and art, provide some value for the research in related fields.
\end{abstract}

\section{Introduction}

With the development of the times and the advancement of science and technology, we have entered a brand-new digital era. And the computer as an important, common digital tool is no longer mysterious, they are quietly changing the way we live, study, and work. Of course, its combination with the direction of art has also sprung up like mushrooms after a rain, this is an inevitable trend in the development of technology and society, technology and art. Since human beings know how to record civilization, they have been creating different visual images. From the wall paintings of the prehistoric Altamira caves to the Marvel universe shown in the current video world, it shows that the creation of art works is more innovative, extended and intuitive due to the participation of computers. Therefore, this article uses computer vision art as a key word, and focuses on the field of animation closely related to computers, in order to provide references for other related topics.

\section{Overview}

\subsection{Computer visual art}

Computer vision, also known as machine vision, is an optical recognition, tracking, and measurement system that uses machines to imitate human vision, and highly complete the task that human can not complete. The computer vision art is due to the continuous improvement of people's quality of life and the continuous development of computer vision, so that people begin to use artistic eyes to examine visual information such as lines, shapes, colors, textures, and spaces, and think about how to get the more diversified and specific and visualization of its performance, so as to show the unique beauty of the category of computer vision, This has become the main direction and focus of computer vision art research.

\subsection{Computer animation}

Animation is not equal to cartoons. It is a comprehensive art expression form that integrates painting, comics, movies, digital media, photography, music, literature and many other art categories. It is the art of creating life movement through painting. Throughout it's historical changes, it is closely connected with the development of computers. Whether it is the transition from paper animation to paperless animation, or the transition from two-dimensional animation to three-dimensional animation, it all illustrates the importance of computers. Moreover, emoji that are widely used in social interaction are also a new language symbol in the field of animation. It is not only vivid and interesting, but also effective in conveying information, and is very popular among the public.

\section{Computer vision art application based on emoticons}

Computer visual art and animation complement each other, mainly due to the development of science and technology and the arrival of the data age, making computer visual art gradually move towards the civilianization and popularization of serving the masses. Among them, the emoticon is a typical branch of the animation field. It's creation can be divided into three content: the early stage, the middle stage and the late stage (Figure 1). Each part of which can not be separated from the application of computer vision art. The following is based on Yuxin Wang's "Fairy Frog" as an example to illustrate.

\footnotetext{
*Corresponding author: 626276535@qq.com
} 


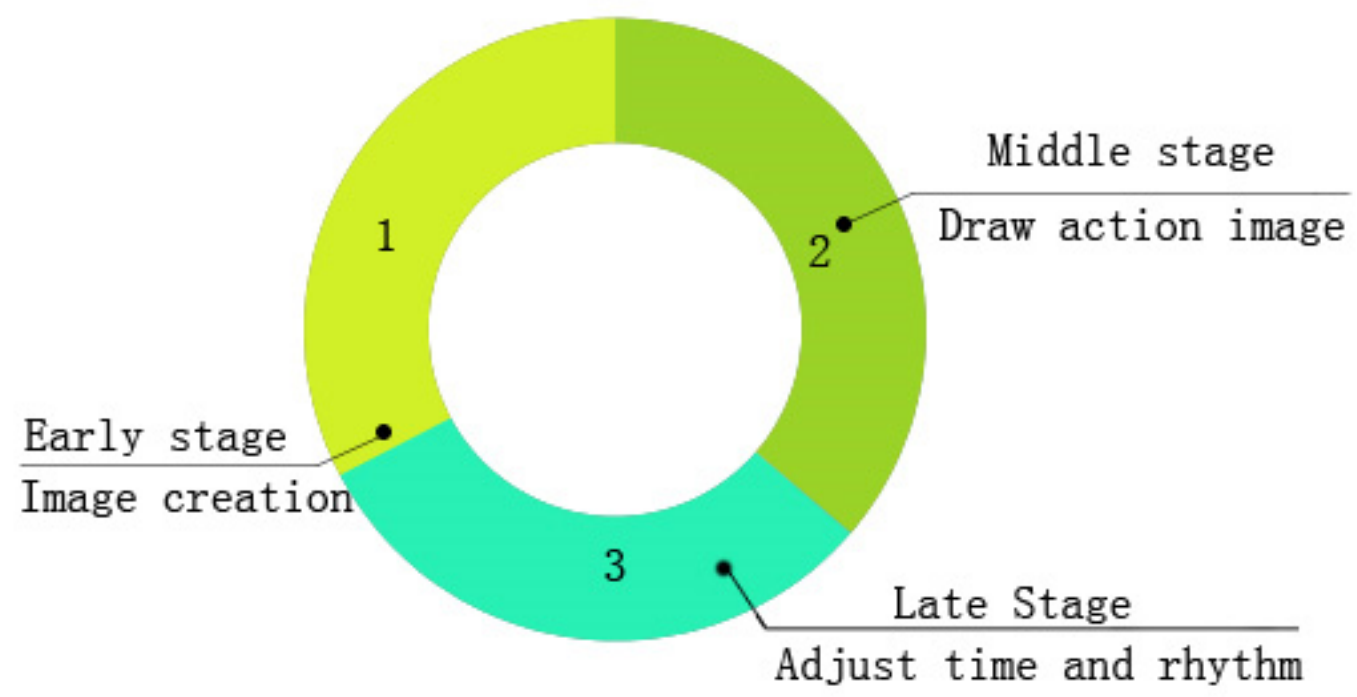

Figure 1. The creative process of emoticons

\subsection{Early stage}

This stage mainly refers to the creation process of facial expressions. Creators can use computer-related software to create virtual cartoon images at any time. Because computer images are stored in digital form, different images can be composed according to different colors and different arrangements. I have learned from the author that in the early stage of creation of "Fairy Frog", it was clear that we should use simple techniques to draw cute expressions, so the image of frogs with fleshy faces and round eyes can be completed. Figure 2 is a turned side view of the image; in addition, everyday green frogs appear everywhere, there is no new idea, so I switched to the corresponding red color to reduce the saturation and increase the brightness to determine the main hue of the current pale pink. At the same time, in order to enhance the expressiveness of the picture, some dark pinks with low brightness and medium saturation were added to the body. As a decorative color (if you put it on the face, you will feel top-heavy and uncomfortable); in addition, the overall picture still lacks a color with high saturation, otherwise the overall image is gray and lacks cuteness and agility. Therefore, the pink with high saturation and moderate brightness was selected for embellishment on the cheeks. After confirming the image, design according to the preset content such as crazy hint, look at you quietly, under a lot of pressure and so on. Use personal imagination and emotional expression to design corresponding postures, actions, expressions, etc, so usually people from the expression of the visual image is no longer a simple information, but a kind of emotional expression and artistic enjoyment. At the same time, because of the wider use of emoticons, it also greatly enhances people's understanding of computer visual art.

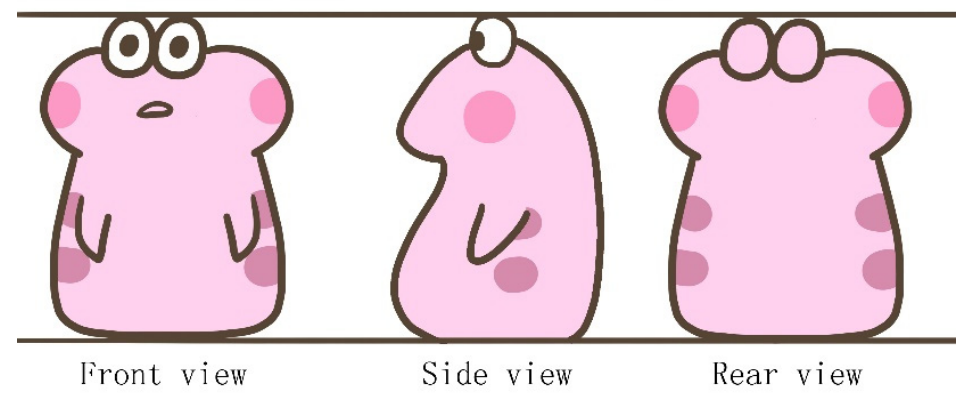

Figure 2. A turned side view of the image

\subsection{Middle stage}

Animation is a moving art. At this stage, the middle picture is drawn on the basis of the image. Put one picture after another in sequence by the visual persistence principle to express and finally make the emoticons from static to dynamic. Transformation has the function of connecting the preceding and the following. Figure 3 is the sequence frame display of the emoticon. Table 1 is the creation process of sequence frames. In this process, computer vision art is mainly manifested in examining the rationality, artistry, and fun of the action, such as the emoticon of "Crazy Hint" for red envelopes, as the falling of red envelopes and the details of the friction between hands can not only stimulate the audience's the sensory experience, also helps to strengthen the understanding of 
the emotion and even the creativity that the image creator wants to express, which all reflects the beauty of the integration of technology and art.
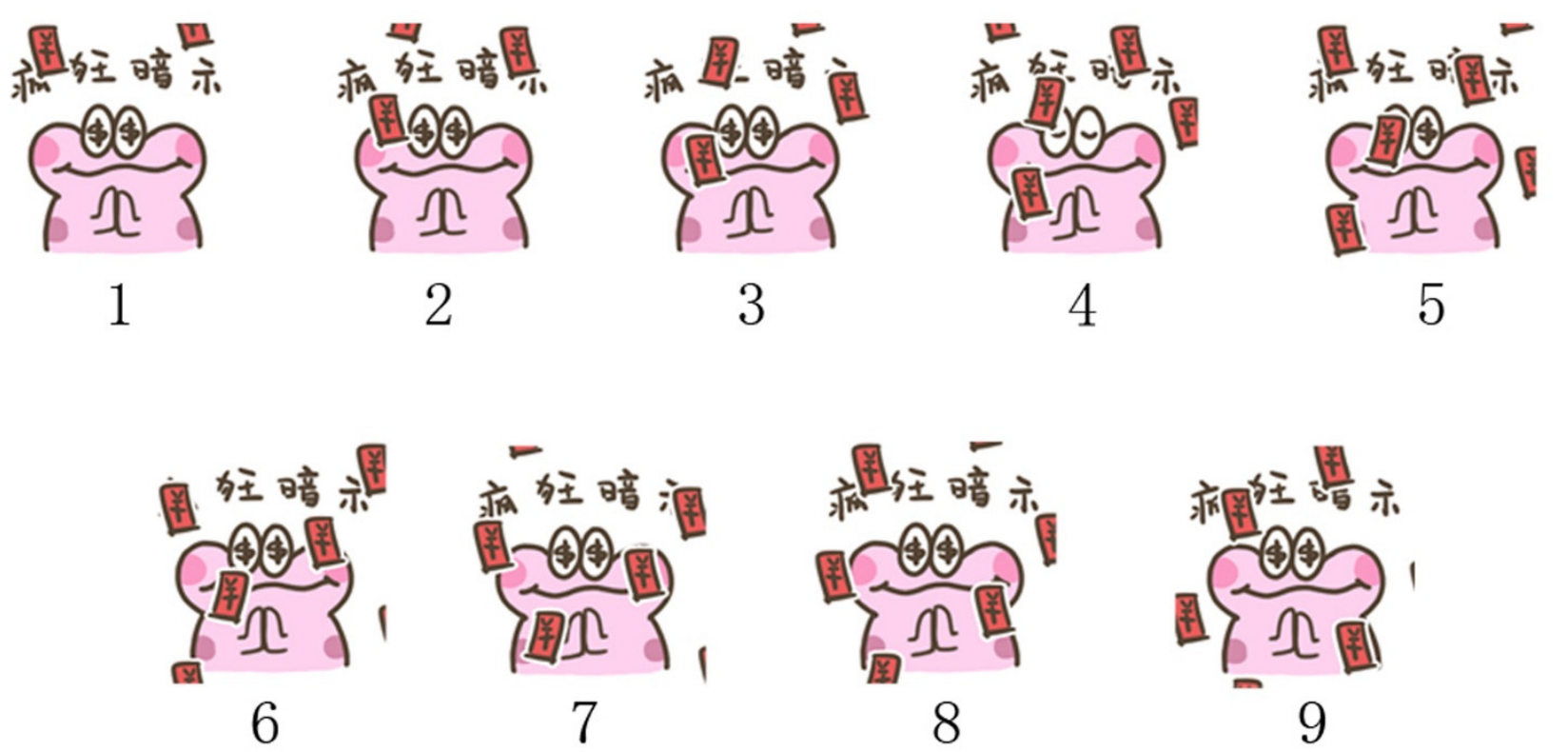

Figure 3. Sequence frame display

Table1. The creation process of sequence frames

\begin{tabular}{|c|c|}
\hline Number of frames & $1-9$ \\
\hline Original picture & $1,5,9$ (The first frame is the same as the ninth frame) \\
\hline Middle picture & $2,3,4,6,7,8$ \\
\hline $\begin{array}{c}\text { The method of drawing middle } \\
\text { picture }\end{array}$ & $\begin{array}{l}\text { Draw } 3 \text { frames through } 1 \text { frame and } 5 \text { frames. } \\
\text { Draw } 2 \text { frames through } 1 \text { frame and } 3 \text { frames. } \\
\text { Draw } 4 \text { frames through } 3 \text { frame and } 5 \text { frames. } \\
\text { Draw } 7 \text { frames through } 5 \text { frame and } 9 \text { frames. } \\
\text { Draw } 6 \text { frames through } 5 \text { frame and } 7 \text { frames. } \\
\text { Draw } 8 \text { frames through } 7 \text { frame and } 9 \text { frames. }\end{array}$ \\
\hline Effect & $\begin{array}{l}\text { The second picture has more red envelopes than the first one and has a } \\
\text { lower position. } \\
\text { The third picture has more red envelopes and a lower position than the } \\
\text { second one, and so on. } \\
\text { In the end, look at the picture together will show the effect of the red } \\
\text { envelope gradually falling. }\end{array}$ \\
\hline
\end{tabular}

\subsection{Late stage}

There is an old saying in China that "The focus is on the finishing of the basket". This stage is the last link. It is mainly responsible for adjusting the time and rhythm of the still image combination in order to achieve a more infectious, lifelike, coherent, complete, and logical artistic effect. I will take the "Crazy Hint" expression as an example. Each frame is set to a suitable 0.2 second (Table 2 ). At the same time, taking into account the overall unity, the original state of the eighth frame with eyes closed is changed to the state with eyes open, so that the viewer's attention will not be focused on the over-frequency blinking, but pay more attention to the falling red envelopes, and let the audience can fully experience the beauty of speed presented by computer vision art. 
Table2. Time and frequency

\begin{tabular}{|c|c|c|c|}
\hline Time & Effect & Frequency & Effect \\
\hline 0.1 second & Fast & Wink once & Suitable \\
\hline 0.2 seconds & Suitable & Wink twice & Frequently \\
\hline 0.3 seconds & Slow & Wink thrice & Over-frequency \\
\hline
\end{tabular}

\section{Conclusions}

In summary, the wide application of emoticons is an inevitable trend in the development of technology and art, rationality and sensibility. Computer visual art closely revolves around the entire process of making emoticons, which not only brings people a rich visual art experience, abundant emotional expression, also can easily promote the development of artistic effects in the direction envisaged by art designers, and even continuously inspire their creative inspiration to sublimate the art. Therefore, strengthening related research can not only bring out the value of computer vision art, but also can highlight its artistic charm.

\section{References}

1. Guo Sen. Digital Media: Application of Computer Visual Art. Artwork Appreciation. 2019.9

2. Zhao Yuan. Application of Computer Vision Art in Digital Media. Information and Computer (Theoretical Edition). 2018.6

3. Shen Ran. Research on the Application of Computer Vision Art in Digital Media Art. Research on Communication Power. 2019.8

4. Wang Kunhao. Research on the Application of Computer Vision Art in Digital Media Art. Technology Wind. 2017.11

5. Cao Kun. Application of Computer Visual Art in Digital Media. Information and Computer (Theoretical Edition). September 2018.9

6. Yan Yajun. Technology and art complement each other from the perspective of computer programming. The Grand View of Fine Arts. 2008.9

7. Liu Xiao. Wang Huixia. Research on the Application of Computer Visual Art in the Field of Digital Media. Internet World. 2015.7 